\title{
OTOLOGY
}

\section{Surgical outcomes of tympanoplasty using a sterile acellular dermal allograft: a prospective randomised controlled study}

\author{
Outcome chirurgici nella timpanoplastica con graft dermico acellulare: \\ studio prospettico randomizzato controllato
}

\author{
J.M. LEE ${ }^{1}$, Y.J. SEO ${ }^{2}$, D.B. SHIM ${ }^{3}$, H.J. LEE ${ }^{*}$, S.H. KIM ${ }^{4}$ \\ ${ }^{1}$ Department of Otorhinolaryngology, Ilsan Paik Hospital, Inje University College of Medicine, Goyang, Korea; \\ ${ }^{2}$ Department of Otorhinolaryngology, Yonsei University Wonju College of Medicine, Wonju, Korea; ${ }^{3}$ Department \\ of Otorhinolaryngology, Myongji Hospital, Goyang, Korea; ${ }^{4}$ Department of Otorhinolaryngology, Yonsei University \\ College of Medicine, Seoul, Korea \\ * Present address: Department of Otorhinolaryngology-Head and Neck Surgery, Incheon St. Mary's Hospital, College of Medicine, The Catholic \\ University of Korea
}

\begin{abstract}
SUMMARY
Acellular human dermal allografts have been shown to be effective for soft-tissue implantation. We compared treatment outcomes of tympanoplasty using tragal perichondrium and acellular human dermal allograft $\left(\right.$ MegaDerm $\left.{ }^{\circledR}\right)$. In a prospective randomised controlled study, 60 patients scheduled to undergo tympanoplasty were randomly assigned to the autologous tragal perichondrium group $(\mathrm{n}=33)$ or acellular human dermal allograft group $(n=27)$. Postoperative hearing gain, graft success rate at 1 and 6 months and operation times were compared between groups. Graft success rate, defined as the complete closure of tympanic membrane perforation, did not show any significant intergroup difference $(75.8 \%$ vs $85.2 \%, p=0.519)$. Air conduction thresholds and air-bone gaps showed significant improvements in both groups; from $38.7 \pm 15.9 \mathrm{~dB}$ to $30.2 \pm 15.6 \mathrm{~dB}(\mathrm{p}<0.001)$ and from $17.8 \pm 7.3 \mathrm{~dB}$ to $11.5 \pm 7.0(\mathrm{p}=0.001)$ in the autologous tragal perichondrium group, and from $30.4 \pm 12.2 \mathrm{~dB}$ to $24.5 \pm 13.0 \mathrm{~dB}(\mathrm{p}=0.006)$ and from $14.3 \pm 5.1 \mathrm{~dB}$ to $7.6 \pm 4.6 \mathrm{~dB}(\mathrm{p}<0.001)$ in the acellular human dermal allograft group. The amount of hearing gain $(\mathrm{p}=0.31)$ and closure of air-bone gap $(\mathrm{p}=0.863)$ were not meaningfully different between groups. The mean operation time was significantly lower in the acellular human dermal allograft group (35.2 min vs $27.4 \mathrm{~min}, \mathrm{p}=0.039$ ). In this prospective randomised controlled study, acellular human dermal allograft was shown to be an effective alternative to tragal perichondrium, with similar graft success rates and postoperative hearing results, but with reduced operation times.
\end{abstract}

KEY WORDS: Tympanoplasty •Allograft •Acellular dermal matrix • Tympanic membrane perforation

\section{RIASSUNTO}

Gli innesti eterologhi di materiale dermico acellulare hanno dimostrato la loro efficacia nei trapianti di tessuti molli. Nel presente studio sono stati paragonati $i$ risultati derivati dall'utilizzo di pericondrio tragale e da innesto eterologo di materiale dermico acellulare (MegaDerm $\left.{ }^{\circledR}\right)$ negli interventi di timpanoplastica. In modo prospettico randomizzato, 60 pazienti in nota per intervento di timpanoplastica sono stati assegnati casualmente ad un gruppo sottoposto ad intervento che prevedeva ricostruzione con cartilagine tragale $(n=33)$ o con innesto eterologo di materiale dermico acellulare $(n=27)$. Tra i due gruppi sono stati paragonati il guadagno uditivo postoperatorio, il tasso di successo della chirurgia ad 1 e 6 mesi e il tempo operatorio. Il tasso di successo della chirurgia, definito dalla completa chiusura della perforazione della membrana timpanica non ha mostrato alcuna differenza significativa tra i gruppi $(75,8 \%$ vs $85,2 \%, p=0,519)$. La soglia di conduzione per via aerea e il gap tra via aerea e via ossea hanno mostrato invece un significativo miglioramento in entrambi i gruppi considerati, da $38,7 \pm 15,9 \mathrm{~dB}$ a 30,2 $\pm 15,6 \mathrm{~dB}(p<0,001)$ e da 17,8 \pm 7,3 dB a 11,5 \pm 7,0 $(p=0,001)$ nel gruppo di pericondrio tragale autologo; da 30,4 $\pm 12,2 \mathrm{~dB}$ a $24,5 \pm 13,0 \mathrm{~dB}(p=0,006)$ e da 14,3 $\pm 5,1 \mathrm{~dB}$ a 7,6 \pm 4,6 dB $(p<0,001)$ nel gruppo di innesto eterologo di materiale dermico acellulare. La differenza di guadagno uditivo $(p=0,31)$ e la chiusura del gap tra via aerea e via ossea $(p=0,863)$ non sono però risultati significativi tra $i$ gruppi. Il tempo operatorio medio è risultato significativamente minore nel gruppo sottoposto ad innesto eterologo (35,2 min vs 27,4 min, $p=0,039)$. In questo studio prospettico randomizzato controllato, l'innesto eterologo di derma acellulare si è dimostrato come efficace alternativa all'utilizzo di pericondrio tragale, con tasso di successo chirurgico e risultati uditivi simili e minor tempo operatorio.

PAROLE CHIAVE: Timpanoplastica $\bullet$ Innesto eterologo $\bullet$ Matrice acellulare $\bullet$ Perforazione timpanica 


\section{Introduction}

Perforation of the tympanic membrane (TM) is a common disorder encountered by otologists. It is caused by trauma, chronic otitis media, or as a complication of otologic surgeries, and presents with conductive hearing loss. The goals of tympanoplasty are to obtain an intact TM, eradicate pathological tissues in the middle ear and mastoid and reconstruct the sound transmission mechanism. Since first described by Berthold in 1878, various materials have been used for TM grafting ${ }^{1}$. Mostly, tissue located near the operative field is harvested for grafting, and temporalis fascia and tragal perichondrium are the most commonly used grafting materials ${ }^{2}$. These materials may be used solely or compositely such as perichondrium-cartilage island graft ${ }^{3}$. In addition, various allografts, xenografts and alloplasts have been used in tympanoplasty ${ }^{4}$. Among the various materials, human acellular dermal matrix has been used for TM grafting since late 20th century with promising results. However, there has been few prospective randomised trials to provide objective evidence justifying the use of this material. MegaDerm ${ }^{\circledR}$ (L\&C BIO, Seongnam-si, Korea) is one such human acellular dermal allograft derived from donated human skin that is supplied by US tissue banks under the guidelines of the American Association of Tissue Banks and US Food and Drug Administration. It consists of an intact basement membrane matrix processed directly from cadaveric skin, and allows for revascularisation by the recipient's native fibroblasts and endothelial cells ${ }^{5}$. Previous human acellular dermal allografts (e.g., AlloDerm, LifeCell Corp., Branchbug, MJ, USA) are offered as an aseptic material; they are processed using methods to prevent, restrict, or minimise contamination with microorganisms. MegaDerm $^{\circledR}$ is a sterile and non-immunogenic acellular dermal allograft. While processing the material, the cellular components of the epidermis and dermis are removed to allow the graft to be tolerated in the host without inciting an immune response ${ }^{6}$. While sterility cannot be assured in an aseptic condition, MegaDerm ${ }^{\circledR}$ is produced using electron-beam sterilisation to eliminate viruses, bacteria and spores, achieving a $10^{-6}$ sterility level. Thus, theoretically, the use of a sterile allograft may also reduce the risk of infection.

MegaDerm ${ }^{\circledR}$ has been shown to be effective in breast reconstruction ${ }^{7}$, and numerous clinical applications including rhinoplasty, penile augmentation, rotator cuff repair and preventing skin retraction after thyroidectomy and parotidectomy are under investigation. The use of MegaDerm $^{\circledast}$ as a TM graft provides several benefits over native tissue. It can eliminate donor site morbidity, provide enough amount for grafting at any time and preserve native tissue for later use. In revision cases, in which the native tissue has already been consumed, it can be a good alternative available in infinite quantity. Moreover, since the procedures for harvesting and preparing graft tissue are unnecessary, operation times can also be reduced.

Herein, we compared a group of similar, consecutive patients undergoing type I tympanoplasty using MegaDerm $^{\circledR}$ and native tissue (tragal perichondrium) in a prospective randomised controlled study. We compared outcomes of successful closure of TM perforation, audiologic outcomes and operation times for the different graft materials.

\section{Materials and methods}

\section{Patients}

Sixty patients who underwent type I tympanoplasty for TM perforation between March 2015 and March 2016 were included in the study. They were between 14 and 79 years of age (mean age $=53.3$ years); $17(28.3 \%)$ were men and $43(71.7 \%)$ were women. Patients who underwent other procedures (e.g., ossiculoplasty or mastoidectomy) simultaneously were excluded. None had a history of previous ear surgery, and their ear canal and middle ear were completely dried up without otorrhoea. Preoperative records showed that all of the perforations failed to close spontaneously over a 6-month period. They were randomly assigned to the native-tissue group (tympanoplasty using tragal perichondrium) or the MegaDerm ${ }^{\circledR}$ group (tympanoplasty using MegaDerm ${ }^{\circledR}$ ). A third person assigned patients to each group by using a random number table, and informed the surgeon which materials were to be used on the same day of surgery. TM perforation was assessed using a $0^{\circ}, 3 \mathrm{~mm}$ diameter straight telescope (Karl Storz GmbH \& Co. KG, Tuttlingen, Germany) and a high-definition liquid crystal display monitor (Olympus, Tokyo, Japan). The perforations were grouped according to Saliba's subdivision ${ }^{8}$ as follows: small, less than $25 \%$ and less than 1 quadrant size of the total TM; medium, more than $25 \%$ and less than $50 \%$, and more than 1 quadrant and less than 2 quadrant size; large, more than $50 \%$ but not total, and more than 2 quadrant size but not total; and total, 100\% and 4 quadrant size. Patient information is listed in Table I. All procedures were in accordance with the Declaration of Helsinki of 1964. The study was approved by the Institutional Review Board of the Severance Hospital in Seoul, Korea (approval number: 4-2014-1072) and informed consent was obtained from all enrolled patients before surgery. 
Table I. Demographic and clinical characteristics of the study groups.

$\begin{array}{lccc}\text { Variables } & \begin{array}{c}\text { Native Tissue } \\ \text { Group } \\ (\mathbf{n}=33)\end{array} & \begin{array}{c}\text { MegaDerm } \\ \text { Group } \\ (\mathbf{n}=27)\end{array} & \text { P value } \\ \text { Age (yr) } & 53.7 \pm 15.2 & 52.8 \pm 13.5 & 0.808 \\ \text { Sex, } \mathrm{n}(\%) & 13(39.4 \%) & 4(14.8 \%) & 0.031 \\ \text { Male } & 20(60.6 \%) & 23(85.2 \%) & \\ \text { Female } & & & 0.244 \\ \text { Site of graft, n (\%) } & 16(48.5 \%) & 9(33.3 \%) & \\ \text { Right } & 17(51.5 \%) & 18(66.7 \%) & \\ \text { Left } & & & 0.295 \\ \text { Perforation Size, } \mathrm{n}(\%) & 16(48.5 \%) & 13(48.1 \%) & \\ \text { Small } & 16(48.5 \%) & 9(33.3 \%) & \\ \text { Medium } & 1(3.0 \%) & 4(14.8 \%) & \\ \text { Large } & 0(0) & 1(3.8 \%) & \\ \text { Total } & & & \\ \text { Hearing level (dB HL) } & 41.6 \pm 18.2 & 36.4 \pm 17.1 & 0.266 \\ \text { Air conduction } & 23.4 \pm 17.0 & 20.9 \pm 14.9 & 0.548 \\ \text { Bone conduction } & 18.1 \pm 6.8 & 15.5 \pm 5.3 & 0.106 \\ \text { Air-bone gap } & \end{array}$

\section{Surgical procedure}

All patients underwent type I tympanoplasty via the transcanal approach under local anaesthesia. An ear speculum was inserted into the external auditory canal to visualise the perforation. The margins of the perforation were trimmed by using a sharp pick. Then, the tympanomeatal flap was elevated, and the graft material was placed via an underlay technique. After grafting, the external auditory canal was packed with antibiotic-coated gelfoam and sealed using an aseptic cotton ball and plaster. Patients were prescribed broad-spectrum oral antibiotics for 1 week. All patients were discharged the same day.

In the native-tissue group, the tragal perichondrium was harvested as the graft. An additional skin incision was made over the tragus, and the perichondrium was harvested. Thereafter, the incision site was sutured with 4-0 nylon. In the MegaDerm ${ }^{\circledR}$ group, a $1.5 \times 2 \mathrm{~cm}$ graft (thickness $=0.3-0.5 \mathrm{~mm}$ ) was used.

\section{Assessment of treatment outcomes}

Packing materials were completely removed at 2 weeks postoperatively, and the TM was assessed at 1 and 6 months using the same device described above. Graft success was defined as closure of the TM perforation.

All patients underwent pure-tone audiography before, and at 1 and 6 months after surgery. Pure-tone air conduction (AC, 250-8,000 Hz) and bone conduction (BC, $250-4,000 \mathrm{~Hz}$ ) thresholds were measured using clinical audiometers in a double-walled audio booth. The average hearing threshold and air-bone gap (ABG) was defined as the mean value of the measurements taken at frequencies
$500 \mathrm{~Hz}, 1 \mathrm{kHz}, 2 \mathrm{kHz}$, and $3 \mathrm{kHz}$. Postoperative hearing gain and closure of $\mathrm{ABG}$ were calculated by subtracting the mean preoperative $\mathrm{AC}$ thresholds from the mean postoperative AC thresholds, and by subtracting the postoperative $\mathrm{ABG}$ from the preoperative $\mathrm{ABG}$ in both groups, respectively. Any complications that developed during the follow-up period were analysed.

\section{Operation time}

Operation time, defined as the interval between the time of ear speculum insertion into the ear canal and time of postoperative dressing application, was analysed.

\section{Statistical analysis}

Statistical analysis was performed using IBM SPSS Statistics for Windows, Version 21.0 (IBM Corp., Armonk, NY, USA). The results of multiple experiments are presented as the mean \pm standard deviation. Comparisons between continuous variables in two groups were performed using a Student's t-test or the paired t-test for evaluating differences between two groups if the normality test was passed. Otherwise, the Mann-Whitney test or Wilcoxon signed rank test were applied. Comparisons between nominal variables in two groups were performed using Fisher's exact test. A p value of 0.05 was considered as the threshold for significance.

\section{Results}

Among 60 patients, 27 (45.0\%) received MegaDerm ${ }^{\circledR}$. Preoperative hearing level and ABGs for the two groups were not significantly different $(p>0.05$, Table I). Age, perforation size and site of graft were not significantly different between the groups ( $p>0.05$, Table I), but the number of female patients was higher in the MegaDerm ${ }^{\circledR}$ group $(\mathrm{p}=0.031$, Table I).

\section{Success in closing TM perforations}

At 1 month postoperatively, 53 perforations were closed. However, six perforations in the native-tissue group $(18.2 \%)$ and two in the MegaDerm ${ }^{\circledR}$ group $(7.4 \%)$ remained. The success rates for the two groups at 1 month were not significantly different $(\mathrm{p}=0.276)$.

Among six perforations in the native-tissue group, two spontaneously closed at 6 months postoperatively. Three perforations remained at 6 months; but since their sizes were small and the patients were free from any ear symptoms; revision surgeries were not necessarily performed (Fig. 1A). One patient with remnant perforation needed revision surgery. It was a small-sized perforation located on the anteroinferior quadrant of the TM preoperatively 


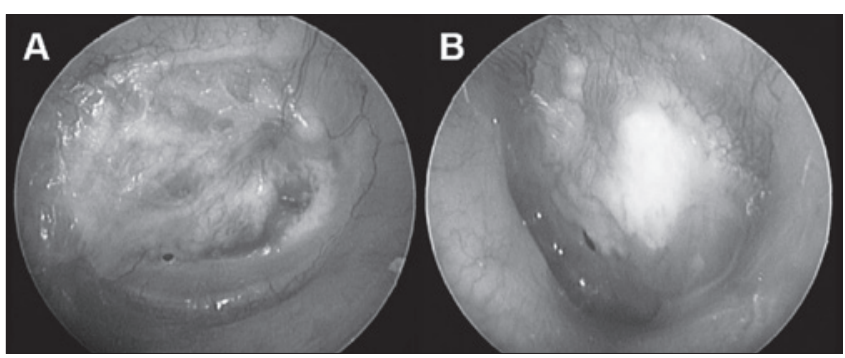

Fig. 1. Representative postoperative tympanic membrane (TM) findings. pin-point perforation developed at 1 month postoperatively and was observed without treatment in the native-tissue group (A) and MegaDerm ${ }^{\circledR}$ group (B).

(Fig. 2A), and a new perforation developed in the posterior margin of the TM after tympanoplasty (Fig. 2B). Four perforations newly developed at 6 months postoperatively. Three of these were followed up without revision surgery for the same reasons as above; however, one perforation needed revision surgery. It was initially a medium-sized perforation (Fig. 2C) and was completely closed at 1 month postoperatively. At 6 months, an otoscopic examination revealed a small-sized perforation with granulation tissue and otorrhoea growing in the middle ear space (Fig. 2D). Consequently, the graft success rate for the native-tissue group at 6 months was $75.8 \%$ (25/33), with two revision surgeries and six small pinpoint perforations.

In the MegaDerm ${ }^{\circledR}$ group, two perforations were observed at 1 month postoperatively, and one needed revision surgery. One was a large-sized perforation preoperatively (Fig. 2E), and had minimally decreased in size at 1 month postoperatively (Fig. 2F); therefore, revision surgery was performed. The other perforation was observed without additional treatment (Fig. 1B). Two perforations newly developed at 6 months postoperatively, and their sizes were so small that they were not treated. Therefore, the graft success rate for the MegaDerm ${ }^{\circledR}$ group at 6 months was $85.2 \%$ (23/27), with one revision surgery and three small pin-point perforations.

Consequently, 25 perforations from the native-tissue group and 23 perforations from the MegaDerm ${ }^{\circledR}$ group were successfully incorporated into the host TM without perforation (Fig. 3). The success rates for the two groups at 6 months were not significantly different $(\mathrm{p}=0.519)$.

We next determined if the graft success rate was dependent on the size and location of the perforation. Among the eight perforations in the native tissue group in which perforations failed to close, four were small-sized, and four were medium-sized. Among the four perforations in the MegaDerm ${ }^{\circledR}$ group, two were small-sized, one was medium-sized and

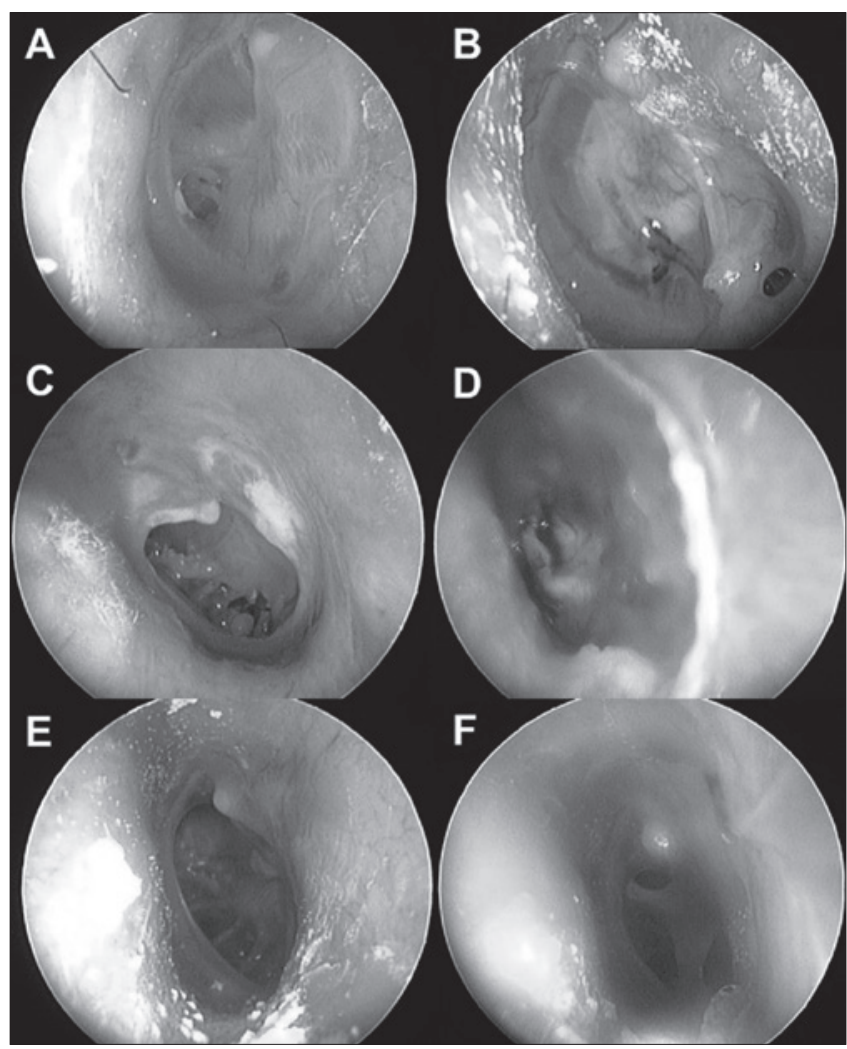

Fig. 2. Tympanic membrane (TM) photographs in patients who underwent revision surgeries. Two patients from the native-tissue group $(A-D)$ and one from the MegaDerm ${ }^{\circledR}$ group ( $\mathbf{F}$ and $\left.\mathbf{G}\right)$ underwent revision surgeries $(\mathbf{A}, \mathbf{C}$ and $\mathbf{E}$ represent preoperative TM findings; $\mathbf{B}$ and $\mathbf{F}$ represent TM findings at 1 month postoperatively; $\mathbf{D}$ represents TM findings at 6 months postoperatively).

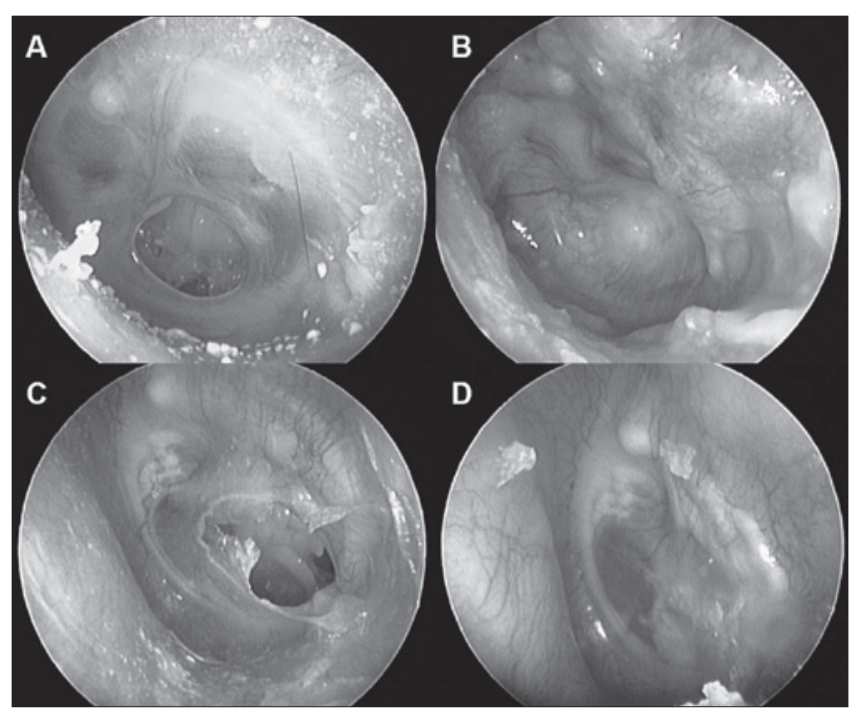

Fig. 3. Otoscopic views of the TM before and at 6 months postoperatively with complete TM closure. Approximately $75.8 \%$ of perforations in the native-tissue group (A, B), and 85.2\% in the MegaDerm ${ }^{\circledR}$ group (C, D) showed successful closure, and the success rate was not significantly different between the two groups $(p=0.519)$. 
Table II. Perforation size and location.

\begin{tabular}{|c|c|c|}
\hline Variables & $\begin{array}{l}\text { Native Tissue Group } \\
\qquad(\mathrm{n}=33)\end{array}$ & $\begin{array}{l}\text { MegaDerm Group } \\
\qquad(\mathrm{n}=27)\end{array}$ \\
\hline $\begin{array}{l}\text { Small } \\
\text { - Anterosuperior } \\
\text { - Anteroinferior } \\
\text { - Posterosuperior } \\
\text { - Posterioinferior } \\
\text { - Central }\end{array}$ & $\begin{array}{c}16(48.5 \%) \\
4 \\
11 \\
0 \\
0 \\
1\end{array}$ & $\begin{array}{c}13(48.1 \%) \\
0 \\
11 \\
0 \\
1 \\
1\end{array}$ \\
\hline $\begin{array}{l}\text { Medium } \\
\text { - Anterior } \\
\text { - Posterior } \\
\text { - Inferior } \\
\text { - Central }\end{array}$ & $\begin{array}{c}16(48.5 \%) \\
7 \\
0 \\
6 \\
3\end{array}$ & $\begin{array}{c}9(33.3 \%) \\
4 \\
1 \\
4 \\
0\end{array}$ \\
\hline Large & $1(3.0 \%)$ & $4(14.8 \%)$ \\
\hline Total & $0(0)$ & $1(3.8 \%)$ \\
\hline
\end{tabular}

The proportion of perforation sites in the small-sized and medium-sized perforations did not differ significantly between groups ( $p=0.215$ and $p=0.528$, respectively). Graft success rates did not differ based on perforation size (small vs medium, $p=0.303$ ) or location (anterior vs posterior, $p=0.503$ ).

one was large-sized. In the native tissue group, two of the small-sized perforations were located anterosuperior and two were anteroinferior. In the native tissue group, one of the medium-sized perforations was located centrally, one was anterior and two were inferior. Two small-sized perforations of MegaDerm ${ }^{\circledR}$ group were located at anteroinferior quadrant of the drums, and a medium-sized perforation of $\mathrm{MegaDerm}^{\circledR}$ group was located at inferior region. Proportion of size and location of the perforations did not significantly differ between groups (Table II).

The size and location of the perforation and graft success rates were analysed. Perforations were initially classified into four groups, anterior small $(\mathrm{n}=26)$, posterior small $(\mathrm{n}=1)$, anterior medium $(\mathrm{n}=11)$ and posterior medium $(n=1)$; the others, such as central or inferior perforations, were excluded due to the small number of cases. Of these, six anterior small-sized perforations and one anterior medium-sized perforation failed to close. However, no statistically significant differences were found between groups $(p=0.694)$ in the size of the perforations $(p=0.303)$ or the location of the perforations $(\mathrm{p}=0.503)$. The overall graft success rate was also not significantly different between the two groups $(p=0.519)$. There was no difference in the successful closure of TM perforation based on size, location, or graft materials (Table II).

\section{Hearing results}

At 1 month postoperatively, the AC threshold improved from $41.6 \pm 18.2 \mathrm{~dB}$ to $35.2 \pm 20.1 \mathrm{~dB}(\mathrm{p}<0.001)$, and the $\mathrm{BC}$ threshold stabilised from $23.4 \pm 17.0 \mathrm{~dB}$ to $22.2 \pm 17.6 \mathrm{~dB}(\mathrm{p}=0.057)$ in the native-tissue group. Similar results were observed in the MegaDerm ${ }^{\circledR}$ group. The AC threshold improved from $36.4 \pm 17.1 \mathrm{~dB}$ to
$31.3 \pm 8.6 \mathrm{~dB}(\mathrm{p}<0.001)$, and the $\mathrm{BC}$ threshold stabilised from $20.9 \pm 14.9 \mathrm{~dB}$ to $19.7 \pm 17.1 \mathrm{~dB}(\mathrm{p}=0.240)$. Hearing gain between the two groups was not significantly different ( $p=0.455$, Fig. 4A, 4B). ABG was significantly reduced in both groups, from $18.1 \pm 6.8 \mathrm{~dB}$ to $13.1 \pm 6.4 \mathrm{~dB}(\mathrm{p}<0.001)$ in the native-tissue group and from $15.5 \pm 5.3 \mathrm{~dB}$ to $11.7 \pm 5.7 \mathrm{~dB}(\mathrm{p}=0.002)$ in the MegaDerm ${ }^{\circledR}$ group. Therefore, $\mathrm{ABG}$ was reduced by $5.1 \pm 7.0 \mathrm{~dB}$ in the native-tissue group and by $3.8 \pm 5.7$ $\mathrm{dB}$ in the MegaDerm ${ }^{\circledR}$ group, which was not significantly different ( $p=0.455$, Fig. 5A).

Serial pure-tone audiograms were acquired in 34 patients (17 from each group) at 6 months postoperatively. The other 26 patients referred no discomfort in subjective hearing and refused to undergo hearing tests. The AC threshold improved from $38.7 \pm 15.9 \mathrm{~dB}$ to $30.2 \pm 15.6 \mathrm{~dB}(\mathrm{p}<0.001)$ in the native-tissue group, and from $30.4 \pm 12.2 \mathrm{~dB}$ to $24.5 \pm 13.0 \mathrm{~dB}(\mathrm{p}=0.006)$ in the MegaDerm ${ }^{\circledR}$ group. The BC threshold stabilised from $20.9 \pm 15.4 \mathrm{~dB}$ to $18.8 \pm 15.5 \mathrm{~dB}(\mathrm{p}=0.096)$ and from $16.0 \pm 10.0 \mathrm{~dB}$ to $16.8 \pm 11.1 \mathrm{~dB}(\mathrm{p}=0.522)$ in the nativetissue and MegaDerm ${ }^{\circledR}$ groups, respectively. Hearing gain was not different between the groups ( $p=0.31$, Fig. $4 \mathrm{C}$, 4D). Both groups showed significantly reduced ABGs at 6 months postoperatively: $17.8 \pm 7.3 \mathrm{~dB}$ to $11.5 \pm 7.0$ $(\mathrm{p}=0.001)$ in the native-tissue group and $14.3 \pm 5.1 \mathrm{~dB}$ to $7.6 \pm 4.6 \mathrm{~dB}(\mathrm{p}<0.001)$ in the $\mathrm{MegaDerm}^{\circledR}$ group. The amount of reduction in ABGs was similar between the groups $(p=0.863$, Fig. 5B).

\section{Complications}

Except for the re-perforation or incomplete TM closure described above, few complications were observed. 


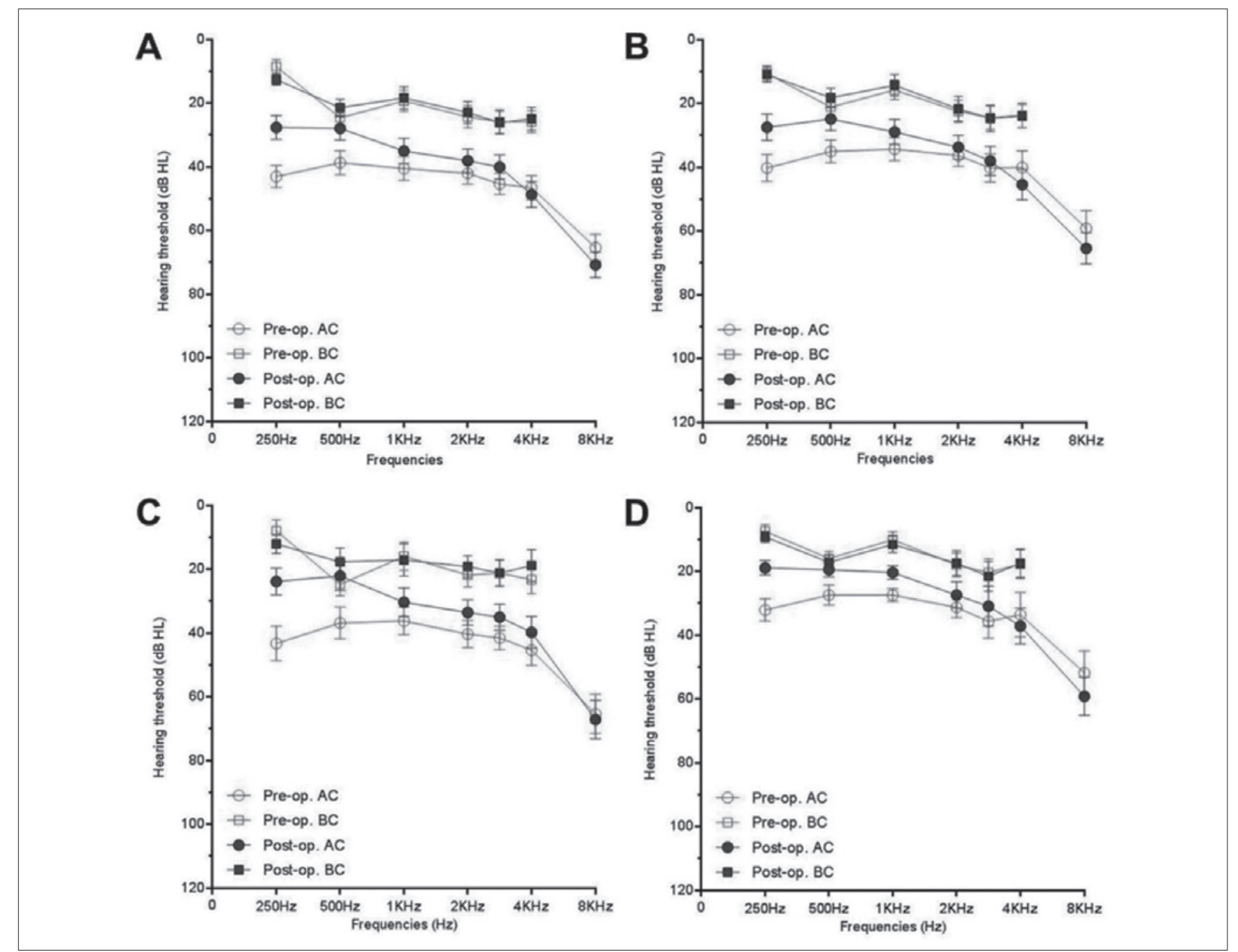

Fig. 4. Preoperative and postoperative hearing results of the native-tissue group and MegaDerm ${ }^{\circledR}$ group measured at $1(\mathbf{A}$, native-tissue group, $n=33$; B, MegaDerm ${ }^{\circledR}$ group, $n=27$ ) and 6 months $\left(\mathbf{C}\right.$, native-tissue group, $n=17 ; \mathbf{D}$, MegaDerm ${ }^{\circledR}$ group, $n=17$ ) postoperatively. The air-conduction thresholds significantly improved in both groups, whereas the bone-conduction thresholds remained stable. The preoperative and postoperative air- and bone-conduction thresholds were not significantly different between the two groups $(p=0.266$ and $p=0.445$ for preoperative and postoperative air-conduction thresholds at 1 month postoperatively; $p=0.548$ and $p=0.584$ for preoperative and postoperative bone-conduction thresholds at 1 month postoperatively; $p=0.096$ and $p=0.252$ for preoperative and postoperative air-conduction thresholds at 6 months postoperatively; $p=0.284$ and $p=0.682$ for preoperative and postoperative bone-conduction thresholds at 6 months postoperatively).

Myringitis was reported in one patient in each group. They were treated with otic solution and oral medication, and the myringitis resolved without re-perforation. However, another patient from the native-tissue group had middle ear infection with re-perforation, requiring revision surgery (Fig. 2B). One patient from the native-tissue group experienced donor-site perichondritis, which resolved without complications after oral medication.

\section{Operation time}

The mean operation time was $35.2 \pm 15.6 \mathrm{~min}$ in the native-tissue group and 27.4 $\pm 13.2 \mathrm{~min}$ in the $\mathrm{MegaDerm}^{\circledR}$ group. The operation times were significantly lower in the MegaDerm $^{\circledR}$ group $(p=0.039)$.

\section{Discussion}

There are several advantages to performing tympanoplasty using a human acellular dermal allograft. First, the operation time can be significantly reduced. In our study, the use of MegaDerm ${ }^{\circledast}$ helped save on average $7.8 \mathrm{~min}$ over the use of tragal perichondrium. The longer operation time for autologous tissue grafting was because of the harvesting and handling of the graft material. Since 


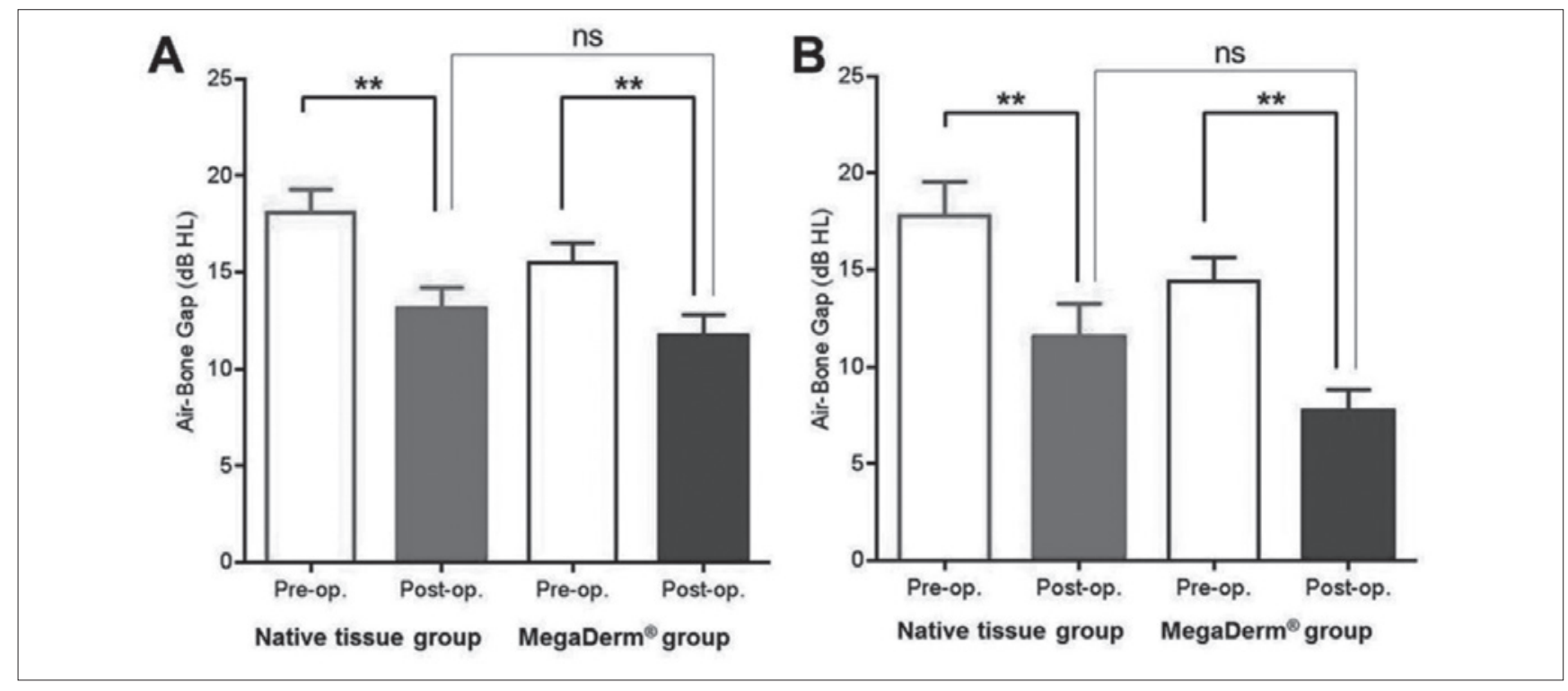

Fig. 5. Changes in air-bone gaps (ABGs) after tympanoplasty (A, at 1 month postoperatively; $\mathbf{B}$, at 6 months postoperatively). Significant reductions in ABGs were observed in both groups, and the amount of reduction of ABGs and postoperative ABGs were not significantly different between the two groups ( $p=$ 0.455 at 1 month postoperatively; $p=0.863$ at 6 months postoperatively).

MegaDerm ${ }^{\circledR}$ is prepared in a dried condition, surgeons do not need to wait for the material to dry as preferred, and can easily trim the material into the proper size and shape. MegaDerm ${ }^{\circledR}$ is as thick as $0.3-0.5 \mathrm{~mm}$, which is generally thicker than native tissues, though still pliable, and the thickness and elasticity provide stability while handling the material.

Second, an additional incision for harvesting the graft material is unnecessary when using MegaDerm ${ }^{\circledR}$, thus reducing donor-site morbidity. In cases in which tympanoplasty is performed via the transcanal approach, an additional incision is mandatory for harvesting the graft material unlike tympanoplasty via the retroauricular approach in which the temporalis fascia can be harvested via the same surgical site. This can reduce the probability of donor-site infection or deformity induced by injury to tragal cartilage. Reported donor-site infection is rare, but cannot be excluded ${ }^{9}$.

Third, the limitless supply of MegaDerm ${ }^{\circledast}$ is another advantage. In cases of revision surgery, finding enough suitable fascia or perichondrium is sometimes difficult, especially if the patient has undergone multiple surgeries. Finding autogenous tissues for grafting can be another time-consuming procedure and may increase donor-site morbidity. The authors also use MegaDerm ${ }^{\circledR}$ in canalwall-down mastoidectomy with tympanoplasty and revision surgery, and the limitless supply of graft material could contribute to stable healing.

MegaDerm ${ }^{\circledR}$ further offers an immunogenic benefit. The safety of acellular dermal matrix allografts has been well demonstrated in both animal ${ }^{1011}$ and clinical studies ${ }^{12}$. Moreover, MegaDerm ${ }^{\circledR}$ is a sterile allograft produced by removing the antigenic target of cell-mediated rejection. A previous study comparing the rate of postoperative infection between sterile allograft and aseptic allograft in breast reconstruction showed the superiority of the immunologic aspects of MegaDerm ${ }^{\circledR 13}$. Although a direct comparison of these two materials in tympanoplasty has not yet been performed or reported, it can be stated that at least there is no harm in utilising MegaDerm ${ }^{\circledR}$ over native tissue or conventional allografts in view of its immunogenic superiority.

In addition to the many advantages described above, MegaDerm ${ }^{\circledR}$ provides comparable functional benefits. Graft success rate varies according to materials and study designs. Success rates reported in retrospective studies were mostly higher than those reported in prospective studies, regardless of the graft material used. In 2008, Gamra et al. reported a success rate of $97.7 \%$ for cartilage from 90 tympanoplasties, and a success rate of $96.9 \%$ for temporalis fascia from 290 tympanoplasties ${ }^{14}$. Solmaz et al. performed 194 tympanoplasties with perichondrium-cartilage island graft, and the success rate was $91.24 \%{ }^{3}$. A few other retrospective studies have reported similar outcomes. However, there are only two prospective studies reporting success rates for cartilage and temporalis fascia. Yung et al. reported $84.2 \%$ and $80.0 \%$ success rates and Mauri 
et al. reported $86.1 \%$ and $88.2 \%$ success rates for temporalis fascia and cartilage ${ }^{15} 16$. The reported success rates are quite comparable to those of $\mathrm{MegaDerm}^{\circledR}$ in this study. The success rate for allografts was similar to those for autologous materials. One study that performed tympanoplasty using allografts showed an $88 \%$ success rate ${ }^{17}$, and another reported a $78 \%$ success rate for TM closure ${ }^{18}$. With respect to hearing results, a prospective study with a large population of 553 patients reported 12 month follow-up data; both $\mathrm{AC}$ and $\mathrm{ABG}$ improved from $32.1 \mathrm{~dB}$ to $29.7 \mathrm{~dB}$ and from $21.2 \mathrm{~dB}$ to $19.1 \mathrm{~dB}$ at 1 year postoperatively, respectively, ${ }^{19}$ and the improvement was comparable to that seen in our study.

Since the first commercial use of allograft in tympanoplasty in 1999, the advantages of this procedure have been widely reported ${ }^{20}$. Numerous studies have provided evidence for its safety and efficacy, including animal studies ${ }^{2122}$ and retrospective studies that compared and analysed methods and results 21723 . To our knowledge, the present study is the first and only prospective randomised controlled study in human patients demonstrating the advantages of the procedure. Therefore, the present study provides stronger support for the safety and efficacy of using allograft in tympanoplasty.

Nevertheless, our study has some limitations. The function of the Eustachian tube highly affects the outcome of tympanoplasty in both disease recurrence and hearing improvement ${ }^{24}{ }^{25}$. Age, site of graft, perforation size and hearing level were matched in both groups, but the function of the Eustachian tube was neither assessed nor compared. Although there is no available definite method that reflects the function of the Eustachian tube, information on preoperative Eustachian tube function could provide better comparison between groups and with previous reports. Second, a 6 month follow-up period is likely to be sufficient to compare the efficacy of the materials; however, for better comparison, longer-term follow-up with more subjects is needed.

\section{Conclusions}

Compared to autologous graft materials, MegaDerm ${ }^{\circledR}$ is an effective alternative as a TM graft material with similar graft success rates and postoperative hearing results, but with reduced operation times.

\section{Conflict of interest statement}

None declared.

\section{References}

1 Glasscock ME, Kanok MM. Tympanoplasty: a chronological history. Otolaryngol Clin North Am 1977;10:469-77.

2 Benecke JE, Jr. Tympanic membrane grafting with alloderm. Laryngoscope 2001;111:1525-7.

3 Solmaz F, Akduman D, Haksever M, et al. The audiological and take results of perichondrium attached cartilage island graft in tympanoplasty: PACIT. Acta Otorhinolaryngol Ital 2016;36:275-81.

4 Boedts D. Tympanic grafting materials. Acta Otorhinolaryngol Belg 1995;49:193-9.

5 Wainwright DJ. Use of an acellular allograft dermal matrix (AlloDerm) in the management of full-thickness burns. Burns 1995;21:243-8.

6 Livesey SA, Herndon DN, Hollyoak MA, et al. Transplanted acellular allograft dermal matrix. Potential as a template for the reconstruction of viable dermis. Transplantation 1995;60:1-9.

7 Lee JH, Park Y, Choi KW, et al. The effect of sterile acellular dermal matrix use on complication rates in implantbased immediate breast reconstructions. Arch Plast Surg 2016;43:523-8.

8 Saliba I. Hyaluronic acid fat graft myringoplasty: how we do it. Clin Otolaryngol 2008;33:610-4.

9 Tseng CC, Shiao AS. Postoperative auricular perichondritis after an endaural approach tympanoplasty. J Chin Med Assoc 2006;69:423-7.

$10 \mathrm{Xu} \mathrm{H}$, Wan H, Sandor M, et al. Host response to human acellular dermal matrix transplantation in a primate model of abdominal wall repair. Tissue Eng Part A 2008;14:2009-19.

11 Lucke S, Hoene A, Walschus U, et al. Acute and chronic local inflammatory reaction after implantation of different extracellular porcine dermis collagen matrices in rats. Biomed Res Int 2015;2015:938059.

12 Jiang DY, Chen B. Clinical study on the immunoregulation effects of cytokines on the acellular xenogenic dermal matrix. Zhonghua Shao Shang Za Zhi 2003;19:351-4.

13 Weichman KE, Wilson SC, Saadeh PB, et al. Sterile "readyto-use" AlloDerm decreases postoperative infectious complications in patients undergoing immediate implant-based breast reconstruction with acellular dermal matrix. Plast Reconstr Surg 2013;132:725-36.

14 Gamra OB, Mbarek C, Khammassi K, et al. Cartilage graft in type I tympanoplasty: audiological and otological outcome. Eur Arch Otorhinolaryngol 2008;265:739-42.

15 Yung M, Vivekanandan S, Smith P. Randomized study comparing fascia and cartilage grafts in myringoplasty. Ann Otol Rhinol Laryngol 2011;120:535-41.

16 Mauri M, Lubianca Neto JF, Fuchs SC. Evaluation of inlay butterfly cartilage tympanoplasty: a randomized clinical trial. Laryngoscope 2001;111:1479-85.

17 Lai P, Propst EJ, Papsin BC. Lateral graft type 1 tympanoplasty using AlloDerm for tympanic membrane reconstruction in children. Int J Pediatr Otorhinolaryngol 2006;70:1423-9. 
18 Laidlaw DW, Costantino PD, Govindaraj S, et al. Tympanic membrane repair with a dermal allograft. Laryngoscope 2001;111:702-7.

19 Aabenhus K, Andersen SA, Srensen MS. Hearing results after tympanoplasty are stable short-term: a prospective database study. Otol Neurotol 2016;37:1335-43.

20 Youssef AM. Use of acellular human dermal allograft in tympanoplasty. Laryngoscope 1999;109:1832-3.

21 Farahani F, Karimi Yazdi A, Ghasemi M, et al. Results of acellular dermis matrix graft used for tympanoplasty in Guinea pig model. Iran J Otorhinolaryngol 2015;27:95-100.
22 Johnson A, Mixson C, Munday J. Suitability of formaldehyde-treated acellular dermis for tympanic membrane repair in chinchillas. Otol Neurotol 2007;28:778-81.

23 Vos JD, Latev MD, Labadie RF, et al. Use of AlloDerm in type I tympanoplasty: a comparison with native tissue grafts. Laryngoscope 2005;115:1599-602.

24 Bellucci RJ. Selection of cases and classification of tympanoplasty. Otolaryngol Clin North Am 1989;22:911-26.

25 Vartiainen E, Nuutinen J. Success and pitfalls in myringoplasty: follow-up study of 404 cases. Am J Otol 1993;14:301-5.

Received: June 28, 2017- Accepted: May 14, 2018

Address for correspondence: Sung Huhn Kim, Department of Otorhinolaryngology, Yonsei University College of Medicine, 50 YonseiRo, Seodaemun-Gu, 120-752 Seoul, Korea. Tel. 82-2-2228-3604. Fax 82-2-393-0580. E-mail: fledermaus@yuhs.ac 